\title{
ILUSTRAR PARA SONHAR E VICE-VERSA: NOTAS SOBRE A EXPOSIÇÃO "ISTO ME LEMBRA UMA HISTÓRIA..." DE EVANDRO MARENDA
}

\author{
Kando Fukushima ${ }^{1}$
}

Um garoto de olhos preocupados cumprimenta alguém. Sua capa de chuva encharcada deixa uma pequena poça de água abaixo de seus pés. Um casal nu parece entoar um cântico e tocar instrumentos musicais sob uma luz radiante. Um rapaz sentado no chão com as pernas cruzadas parece sorrir.

O garoto cumprimentava um peixe, com braços e pernas em "Onde estou (I)" de 2012 (figura 01). O casal nu possui inscrições no corpo onde identificamos seus órgãos internos, de suas cabeças brotam folhas e a luz é irradiada de algo que nos lembra uma genitália feminina na obra "Seres Essenciais" (2012). O rapaz possui em sua cabeça um abacaxi, quase uma Carmen Miranda numa posição de Yoga em "Um bom começo para gostar de algo é ter a liberdade de não gostar” (2012).

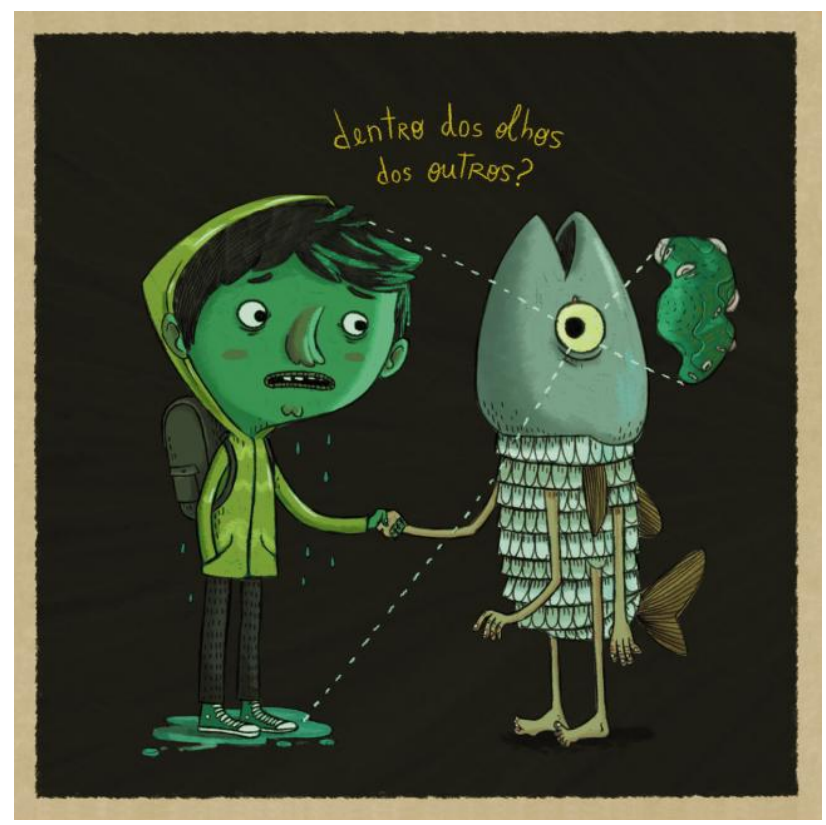

Figura 01: Onde Estou ? (I), 2012. Evandro Marenda.

A exposição "Isto me lembra uma história...", foi a primeira num museu do jovem artista Evandro Marenda, sob curadoria de Ronaldo de Oliveira Corrêa do Museu de Arte da Universidade Federal do Paraná (MusA). Foi composta por 24

${ }^{1}$ Universidade Tecnológica Federal do Paraná, Brasil.

Iluminuras, Porto Alegre, v. 15, n. 35, p. 171-179, jan./jul. 2014 
ilustrações produzidas entre 2009 e 2013 . A "história" do título é a própria narrativa do cotidiano, a rotina, os desejos, as dúvidas, a criatividade, os encontros casuais e a curiosidade despertada pelo estranhamento. Seus personagens são pessoas, na medida em que discutem questões humanas, mas suas aparências muitas vezes nos lembram insetos, animais ou alienígenas. A representação é onírica, com traços, cores e palavras caminhando pelo espaço.

Ilustração, e não pintura ou desenho é também escolha conceitual do artista. Sua proposta é de ilustrar, clarear, trazer à luz suas ideias, como ilustrações de um livro imaginário, de uma história possível. Esse aspecto narrativo pode ser encontrado em qualquer obra da exposição e é algo que ele busca reforçar. O resultado não é um fim em si mesmo, mas algo que é desdobramento de um propósito expressivo sobre questões pessoais que surgem primeiramente na forma de palavras.

A produção apresentada na exposição é algo que Evandro desenvolve paralelamente com suas ilustrações para materiais editoriais sob encomenda. Nesses casos, existe uma negociação mais intensa com outros interesses envolvidos, pois a finalidade é discutida de antemão, as restrições aparecem de forma mais clara. Numa situação, o Saci não deve fumar cachimbo no material didático, noutro o jacaré deve ser inconfundível e qualquer aspecto que crie ambiguidade é retirado. A expressividade de seus desenhos estão presentes, mas não correspondem sempre aos caminhos que escolheria espontaneamente.

Sua formação em Design Gráfico é sentida em sua técnica e pelas referências com que convive, sejam elas da história da arte canônica, através de exposições e leituras, seja ela de desenhos animados, histórias em quadrinhos, cartazes e livros ilustrados, sendo essas últimas as mais evidentes.

Dessa forma, ainda que seja possível estabelecer relações de "Onde estou (I)" com uma obra de Courbet (Bonjour, Monsieur Courbet), ou algum surrealista do século XX, talvez seja mais coerente o diálogo com John Tenniel em seus desenhos para as "Aventuras de Alice no País das Maravilhas" (figura 02) ou mesmo um desenho animado. 


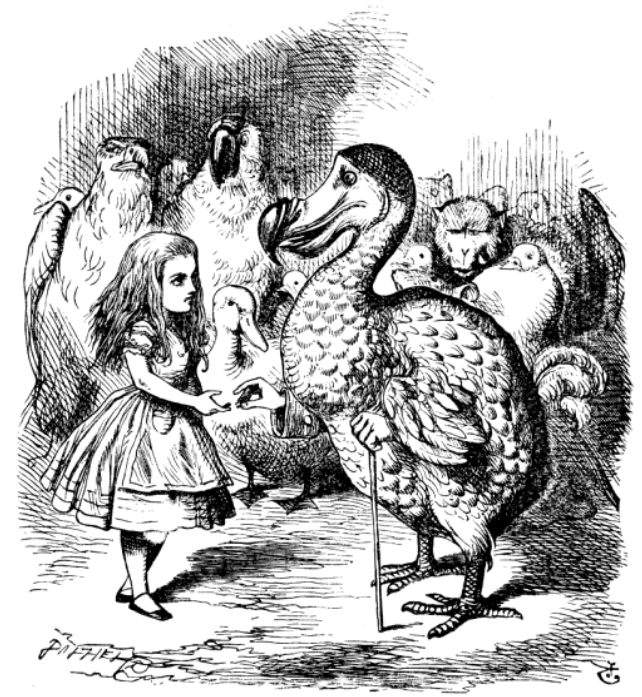

Figura 02: Ilustração de John Tenniel para Alice no País das Maravilhas, 1865. Fonte: http://commons.wikimedia.org/wiki/File:Alice_par_John_Tenniel_09.png

Seu traço, de fato, muitas vezes nos remete a algum desenho de livro infantil, ou uma história em quadrinhos de linguagem visual mais arrojada. A representação bastante estilizada e simplificada é complementada por cores vivas. Em suas distorções, sempre existe algo de cômico e grotesco. Esse diálogo com a visualidade infantil, é reforçado pela própria caligrafia que acompanha grande parte das obras, ou seja, mesmo nos textos, a interpretação não se apoia apenas no que se refere ao significado das palavras em si mas também na morfologia dos caracteres e sua disposição no espaço (figura 03).

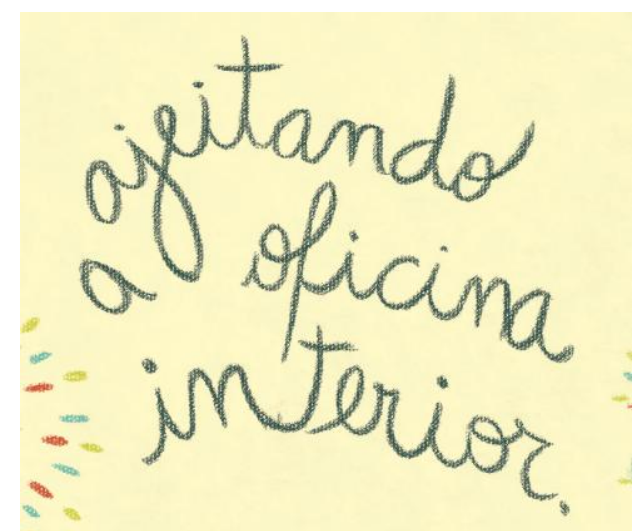

Figura 03: Detalhe da obra Ilustração Ajeitando a oficina interior, 2012. Evandro Marenda.

Segundo o artista, o processo criativo muitas vezes começa pelo texto. Da frase solta sobre o papel, seu esforço inicial é encontrar uma representação visual para o 
conceito a ser abordado. A riqueza dessa tarefa é percebida claramente no processo, onde lembranças e referências pessoais se misturam, e o resultado é fruto de um longo percurso que muitas vezes deixa para trás uma tradução direta do intuito original. Assim, o resultado final não é mera correspondência figurativa do texto, cuja importância é fundamental, mas que está lá para ser ampliado, desviado, reinterpretado. O desenho e as palavras, obra única, é inscrição do processo em si e também de sua imaginação, negociação afetiva e poética do artista com o papel. O desenho feito com nanquim, caneta esferográfica ou lápis é posteriormente colorido no computador. É neste suporte que seus trabalhos de cunho pessoal são mais frequentemente expostos, utilizando principalmente as redes sociais online.

Para a exposição no museu, a maioria das obras foi impressa a partir de arquivos digitais em papel Montval ou Rag, próprios para trabalhos artísticos. A percepção das obras ganhou um novo significado, novas texturas e profundidade. $\mathrm{O}$ fato dos trabalhos estarem reunidos no mesmo espaço, estabeleceu uma noção de conjunto inédita para o artista. A narrativa interna de cada trabalho é complementada por uma narrativa maior. $\mathrm{O}$ humor leve mais evidente em uma obra se contrapõe com a sutil melancolia de outra, estabelecendo ritmo e complexidade.

No museu, além do recorte expositivo, altera-se também a relação com seus leitores, seu público. Acostumados com os suportes online, seus colegas, admiradores desconhecidos ou os praticantes do voyeurismo nas redes sociais, esbarram com fragmentos de sua obra. Nesse meio, questões relacionadas com o valor do original, a sensação tátil dos quadros na parede, a relação de escala e organização com o espaço arquitetônico do museu, o pequeno ritual de contemplação e reflexão comumente exercitado na visita ao museu são transformados em situações corriqueiras, misturadas com outras atividades, evidenciando outros valores. Porém, é justamente nesses meios digitais que são estabelecidas novas formas de comunicação entre o artista e seu público, aspectos muito importantes em sua produção.

Ele encontra nesse meio a crítica e comentários de seus trabalhos, entra em contato com outros artistas, compartilha e estabelece relações criativas com trabalhos de outras pessoas, independentemente delas serem do meio artístico. Evandro ainda admite o hábito quase ininterrupto de busca de referências e inspiração através das ferramentas online. O contexto privilegia muitas vezes a quantidade, sobreposição, pequenos pedaços de informação expostos de forma aleatória. Mesmo dessa forma, identificamos uma parcela significativa dos aspectos poéticos de seu trabalho. Esse 
processo gera algumas obras que nos parecem vagamente reconhecíveis, cuja originalidade é fruto de uma combinação específica entre o conceito e resultado visual, ou ainda de uma certa contradição entre eles.

Para pensarmos em sua obra artística, os recursos que utiliza para sua produção exclusivamente textual também ajudam a interpretação de sua obra visual. Para entender mais uma faceta dessa relação, podemos verificar sua conta no Twitter, rede social utilizado originalmente para passar pequenas mensagens ou notícias. Evandro coloca frases de no máximo 140 caracteres (restrição da ferramenta), que evocam seus sentimentos e que novamente parecem recortes de uma narrativa maior. Não é possível saber o quanto é maior, não possui começo e nem fim.

É a superfície de algo mais profundo? Evandro parece não se importar. Em seu "tweet" de 25 de dezembro de 2011 escreve, "talvez seja um pouco mais difícil libertar-se, já que a corda que o prende não existe", ou ainda, em 05 de setembro de 2012, "porque as solas de seus pés são feitas do chão de onde nasceu, sente-se em casa em qualquer lugar que pise". Resta-nos imaginar, investigar evidências ou mesmo aceitar sua incompletude, como a percepção de um acontecimento visto de relance, ou a conversa com uma criança, abruptamente interrompida, desviada, por algo que ela se lembra repentinamente.

A reflexão sobre o momento criativo compartilhado, construído de forma colaborativa é tema de pelo menos duas obras da exposição. Em ambos os casos vemos a relação entre dois seres, com aparências indecifráveis (insetos, caramujos, alienígenas?) interagindo com pedras flutuantes. Em "Somos seres criativos", de 2012, um deles aponta algumas pedras que brilham e parecem estabelecer uma inesperada conexão, evidenciado pela perplexidade do interlocutor, boquiaberto.

Em "Refletimo-nos, criamos consciência", de 2012 (figura 04), um casal dança divertidamente com as pedras que flutuam entre linhas projetadas de seus corpos. Em suas cabeças parecem "brotar" pedras também. Estariam eles compartilhando pedaços de si ou comemoram a descoberta de novas possibilidades? O que eles farão a seguir? Refletir é ao mesmo tempo pensar a respeito de algo e a imagem espelhada do outro. Vemos a influência criativa mútua, mas também o afeto e a alegria. 


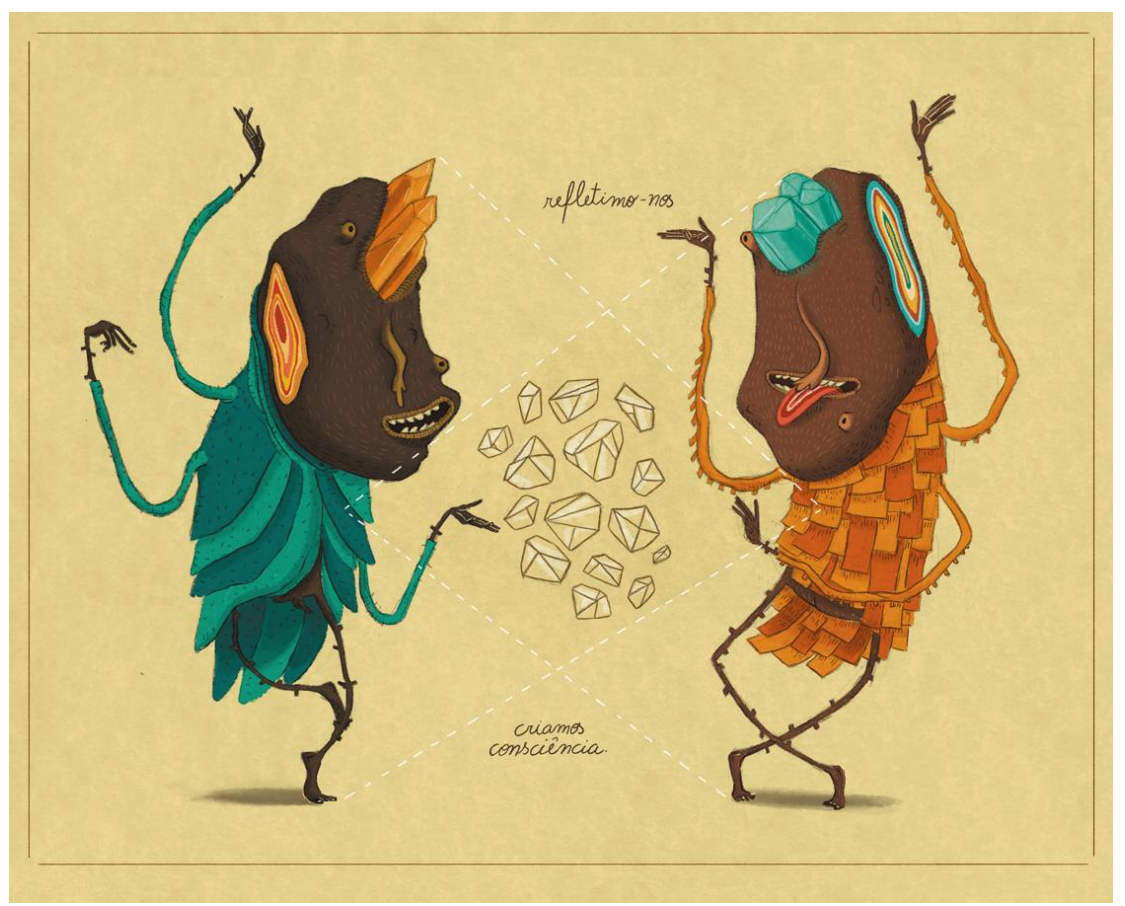

Figura 04: Refletimo-nos, criamos consciência, 2012. Evandro Marenda.

Na obra "Quando eu respiro, respira o mundo que me fez" de 2012 (figura 05), um personagem senta-se numa pedra, com os pés descalços na água. Ele se parece com um alienígena, tem quatro braços, possui um casco como o de uma tartaruga e veste uma roupa parecida com o de astronautas em filmes de ficção científica. Duas mãos estão juntas, como se faz durante uma reza, as outras duas seguram a concha de um animal. Ele lambe o interior da concha. Seu rosto é assimétrico, sua pele laranja e pousado sobre sua cabeça encontramos uma ave, representado de forma bem comportada, sem grandes distorções. As pedras ao seu lado estão cheias de outros animais que se parecem com moluscos aquáticos. Flutuando ao lado temos uma cabeça, parecida com a outra, soltando fumaça pelas narinas. A fumaça parece dar continuidade as linhas projetadas por dois elementos que se parecem com olhos que estão ao seu lado. Acima disso tudo, três rostos surgem da água, um deles parece sugar a água com um canudo.

Apesar dos personagens não serem propriamente bonitos, o conjunto da ilustração é divertido, nos remete a momentos de beleza em nosso cotidiano, a uma lembrança confortável. Talvez seja a ideia de respiração que nos inspira, por certamente não ser aquela ofegante dos dias muito ocupados. Mesmo diante do absurdo, da situação fantástica mirabolante, algo nos pés na água é reconfortante, o personagem que solta fumaça das narinas parece se deleitar, estamos diante de uma 
situação serena, com um ritmo próprio. Os três rostos que olham para o alto deve ser o que podemos vislumbrar de pessoas que estão boiando calmamente.

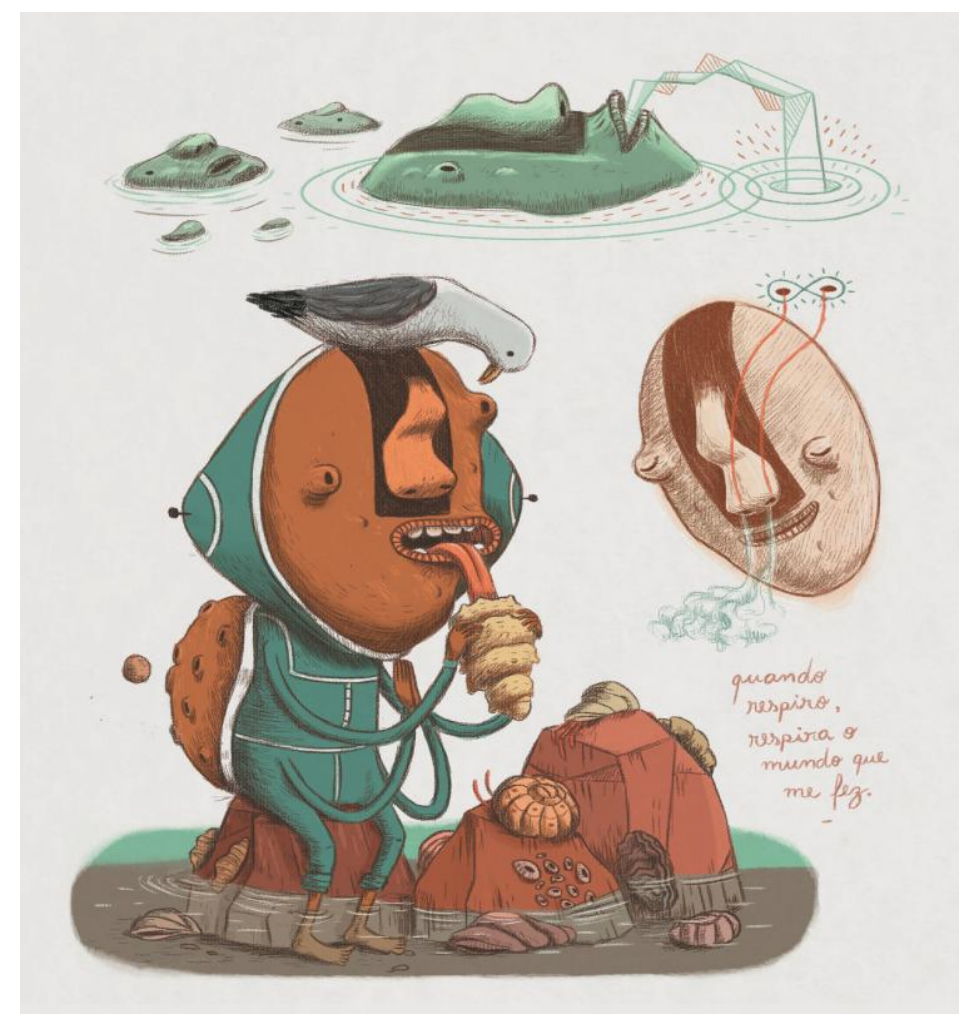

Figura 05: Quando eu respiro, respira o mundo que me fez, 2012. Evandro Marenda.

O conteúdo textual, "Quando eu respiro, respira o mundo que me fez", antes de uma interpretação objetiva, convida o leitor a uma experiência poética, mais sensação do que sentido.

No conjunto da exposição, a série de nove ilustrações "Ex-mágico" é ligeiramente diferente do resto. Trata-se de ilustrações que o autor fez, por escolha própria, de um texto de outro escritor, o conto "O ex-mágico da Taberna Minhota" de Murilo Rubião, publicado originalmente em 1947.

Pode-se dizer que nesse caso, as ilustrações possuem uma abordagem mais convencional, descrevem situações que fazem parte de uma história completa, acabada. O protagonista é visto de diversos ângulos e existe a construção do personagem em suas vistas e expressões faciais diferentes. A linguagem visual possui menos variações, pois pretende dar uma noção clara de continuidade. Esses aspectos nos fazem pensar novamente sobre as possíveis diferenças do contexto de produção de cada ilustração. Por mais que seja perceptível essa característica fundamental, é 
importante destacar a escolha do texto, pois esta trata também do fantástico e do diaa-dia. No conto, um mágico que não controla sua magia, descontente, se torna suicida. Encontra uma "espécie" de morte (e arrependimento) ao se tornar um funcionário público, onde poderia se "suicidar aos poucos", mas em contrapartida acaba perdendo seus poderes fantásticos. A temática é portanto recorrente em seus outros trabalhos, a fantasia e as reflexões sobre a vida e a criatividade.

É curioso que essas foram as únicas ilustrações que foram apresentadas em sua versão anterior à finalização no computador, ainda em preto e branco, apenas com o desenho sobre o papel. Nela podíamos ver os pequenos erros e rabiscos incompletos, sendo que foi possível vislumbrar uma parcela do processo criativo. Elas ainda possuem um sentimento mais claro da noção de "original", num estado "imaculado" em relação à ação do computador e de seu posterior potencial de reprodutibilidade sem fim.

É importante notarmos que podemos considerar a exposição provocativa no que diz respeito ao tema da reprodutibilidade e originalidade. Na longa conversa que tive a oportunidade de realizar com o artista, essas questões apareceram, mas nunca encaradas como problemas fundamentais sob seu ponto de vista. Seja porque está habituado a realizar os trabalhos para serem reproduzidos em massa, para o mercado editorial quando encomendados, seja porque é no meio digital "compartilhável" que suas obras são expostas em primeiro lugar. Ao montar a exposição no MusA, existiu uma grande preocupação em como elas seriam expostas, como imprimir de forma fiel as cores, qual papel e tecnologias seriam as mais adequadas para este propósito. A ideia de exposição, sua curadoria, sua materialização e seu tempo, construiu uma noção renovada de "obra" e somando essas condições ela é original, única. Durante o processo de criação das ilustrações, todos os trabalhos possuem um "original" feito de forma manual, ou melhor, usando instrumentos "físicos" (caneta, lápis, etc.), mas na maioria dos casos o resultado final é fruto de um processo que vai envolver as ferramentas "digitais" (o software utilizado para a pintura digital) que finalmente gera uma "matriz" para os impressos expostos. Mas a obra já existe em sua versão anterior à própria impressão, é ela que circula e é copiada, compartilhada, vista em nos tamanhos reduzidos de telas de celulares ou em grandes monitores de computadores. A exposição no museu é, portanto essencialmente um novo trabalho.

A oportunidade de vermos trabalhos como os de Evandro Marenda num museu estimula uma reflexão mais aprofundada do conjunto da obra do artista, evidenciando 
suas semelhanças e diferenças, trazendo para este espaço manifestações artísticas presentes no cotidiano da produção simbólica, que é transitório a priori. Ainda que seja importante a circulação de seus trabalhos no meios online, reconhecemos que é no espaço do museu que potencializamos um olhar crítico mais elaborado.

As imagens de Evandro evocam ao mesmo tempo ações do cotidiano, o mundo dos sonhos e da imaginação. Ou ainda podemos pensar: evocam o quanto de sonho e imaginação permeiam nosso cotidiano. A combinação de seus desenhos com o texto, muitas vezes frases simples, quase infantis, sugerem sua ideia de narrativa ilustrada. No entanto, a falsa simplicidade dessa estratégia é evidenciada pela exposição de elementos que destoam no contexto pictórico das obras e enriquecem nossa interpretação de seus trabalhos e do mundo ao nosso redor.

\section{Referências}

\section{As obras de Evandro Marenda online:}

https://pt-br.facebook.com/thatremindsmeofastory

http://thatremindsmeofastory.tumblr.com/

https://twitter.com/hectorormano

http://www.behance.net/evandromarenda

\section{Fonte das imagens:}

As imagens das obras da exposição utilizadas foram gentilmente cedidas pelo artista exclusivamente para a publicação deste texto.

\section{Dados da exposição:}

"Isso me lembra uma história..." Ilustrações de Evandro Marenda

Curadoria de Ronaldo de Oliveira Corrêa

Museu de Arte da UFPR / 29 de janeiro a 04 de abril de 2014 